\title{
Kokamidopropil betain ve kokonat dietanolamide bağlı mesleksel alerjik kontakt dermatit
}

\author{
Occupational allergic contact dermatitis due to cocamidopropyl betaine and \\ coconut diethanolamide
}

Mahmut Doğru, Handan Duman, Tayfur Giniș, Serap Özmen, Ilknur Bostancı

Dr. Sami Ulus Kadın Doğum Çocuk Sağlığı ve Hastalıkları Eğitim ve Araștırma Hastanesi, Çocuk Alerjisi Kliniği, Ankara, Türkiye

Özet

Kokamidopropil betain (CAPB) ve kokonat dietanolamid, hindistan cevizi yağından elde edilen, sürfaktan özelliğinde olup şampuan, sivı sabun ve deri temizleyicilerinde yaygın olarak kullanılan kimyasal maddelerdir. Bu maddelerden özellikle CAPB'e karşı alerjik kontakt dermatit (AKD) gelişebilmektedir. İi maddeye karşı gelişen AKD olgusu literatürde az sayıda bulunmaktadır. Burada ellerde kızarıklık, soyulma, çatlama şikayetleri ile başvuran ve kokamidopropil betain ve kokonat dietanolamid bağlı allerjik kontakt dermatit tanısı konulan olgu sunulmuştur. (Türkderm 2013; 47: 180-2)

Anahtar Kelimeler: Kokamidopropil betain, kokonat dietanolamid, allerjik kontakt dermatit

\section{Summary}

Cocamidopropyl betaine (CAPB) and coconut diethanolamide (CDEA), which are manufactured from coconut oil, are widely used as chemical substances with surfactant property in shampoo, liquid soap and skin cleaners. Allergic contact dermatitis (ACD) may occur against these substances, especially cocamidopropyl betaine. ACD developing against these two substances is rarely seen in the literature. Here, we report the case of a patient with ACD caused by CABP and CDEA who presented with complaints of redness, peeling and cracking of the hands. (Turkderm 2013; 47: 180-2)

Key Words: Cocamidopropyl betaine, coconut diethanolamid, allergic contact dermatitis

\section{Giriş}

Kokamidopropil betain (CAPB) ve kokonat dietanolamid (CDEA); hindistan cevizi yağından elde edilirler. Bunlar surfaktan özelliğinde olup şampuan, sıvı sabun, koruyucu krem ve deri temizleyicileri gibi kozmetik ürünlerde yaygın olarak kullanılan kimyasal maddelerdir. Bu maddeleri içeren ürünler kuaförler tarafından sık olarak kullanılmaktadır. Bu maddelerden özellikle CAPB'e karşı alerjik kontakt dermatit (AKD) gelişebilmektedir1,2. CDEA genellikle diğer alerjenlerle birlikte reaksiyona yol açarken CAPD ile birlikte reaksiyona yol açması nadirdir. İki maddeye karşı gelişen AKD olgusu literatürde az sayıda bulunmaktadır. Burada ellerde kızarıklık soyulma, çatlama şikayetleri ile başvuran ve CAPB ve CDEA'e bağlı alerjik kontakt dermatit tanısı konulan olgu sunulmuştur.

\section{Olgu}

On yedi yaşında erkek hasta ellerde kızarıklık, soyulma ve çatlama şikayetleri ile polikliniğimize başvurdu. Özgeçmişinde bayan kuaförü olarak çalışan olgu 18 ay önce saç boyaları ile temas sonrasında ağır astım atağı ile hastanemize yatırıma öyküsü vardı. Astımı kontrol altında idi ve 7 aydır

Yazışma Adresi/Address for Correspondence: Dr. Mahmut Doğru, Dr. Sami Ulus Kadın Doğum Çocuk Sağlı̆ı ve Hastalıkları Eğitim ve Araştırma Hastanesi, Çocuk Alerjisi Kliniği, Ankara, Türkiye GSM: +90 5052703514 E-posta: mdmahmut@yahoo.com Geliş Tarihi/Received: 12.04.2011 Kabul Tarihi/Accepted: 28.06.2011 
koruyucu tedavi almıyordu. Hastanın 2-3 aydır tekrar kuaförlüğe başladığı öğrenildi. Son 2 haftadır şikayetleri vardı. Soygeçmişinde özellik yoktu. Fizik muayenesinde; her iki el parmaklarında eritem, deskuamasyon, fissür ve hiperkeratoz mevcuttu (Resim 1). Diğer sistem muayeneleri normaldi. Alerjik kontakt dermatit olarak değerlendirilen hastaya Avrupa standart seri ("bufexamac", "colophony", "cetylsterylalcohol", "cobalt chloride hexahydrate", "compositae mix", "d,bromodicyanobutane", "dispersions-mix blue", "epoxy resin", "formaldehyde", "fragrance mix II", "fragrance mix", "IPPD", "lyral", "mercapto mix", "2-mercaptobenzothiazole", "CMI/MI", "nickel sulfate hexahydrate", "4-tert-butylphenol formaldehyde resin", "potassium dichromate", "balsam of peru", "propolis", "paraban mix", "thiuram mix", "venice turpentine", "wool alcohols", bis-diethyldithiocarbamato-zinc (Brial Allergen ${ }^{\circledR} \mathrm{GmbH}$, D-Greven, Germany) ile yama testleri Allergeaze Patch test Chamber ${ }^{\circledR}$ kullanılarak yapıldı. 3. gün değerlendirildiğinde reaksiyon saptanmadı. Hastanın kuaförlükte kullandığı malzemeler istendi. Malzemelerin içeriği kontrol edildi. Bu malzemelerin içeriğinde olan ve ünitemizde bulunan hazır ticari alerjenler kullanılarak benzoik asit, formik asit, kokamidopropil betain (\%1), kokonat dietanolamidi $(\% 0,5)$, propilen glikol, trietanolamin, etil alkol (Brial Allergen ${ }^{\circledR} \mathrm{GmbH}$, D-Greven, Germany) ile yama testleri Allergeaze Patch test Chamber ${ }^{\circledR}$ kullanılarak yapıldı. Yama testleri 3. gün değerlendirildiğinde kokamidopropil betain (\%1), kokonat dietanolamidi, $(\% 0,5)$ karşı 2 pozitif duyarlılık saptandı (Resim 2). Hastaya topikal kortikosteroid ve nemlendirici verildi. Hastanın bu maddeleri içeren ürünlerle teması yasaklandı. Meslek değişimi önerildi. Dört hafta sonra hastanın lezyonları kayboldu. Bir yıllık izleminde alerjik kontakt dermatiti tekrarlamadı.

\section{Tartışma}

Kozmetik ürünler sık olarak kullanılmalarına rağmen, alerjik reaksiyonların görülme sıklı̆ı̆ nispeten düşüktür. Avrupa ve Amerika Birleşik Devletleri (ABD)'nde yapılan çalışmalarda genel popülasyonda kozmetik alerji sıklığı \%1'in altında bulunmuştur3,4. Bu sıklık kişilerin hafif alerjik veya iritan reaksiyonlarda doktora gitmeyip, ürün kullanmayı bırakmaları nedeniyle daha düşük olarak saptanmaktadır. Kozmetik

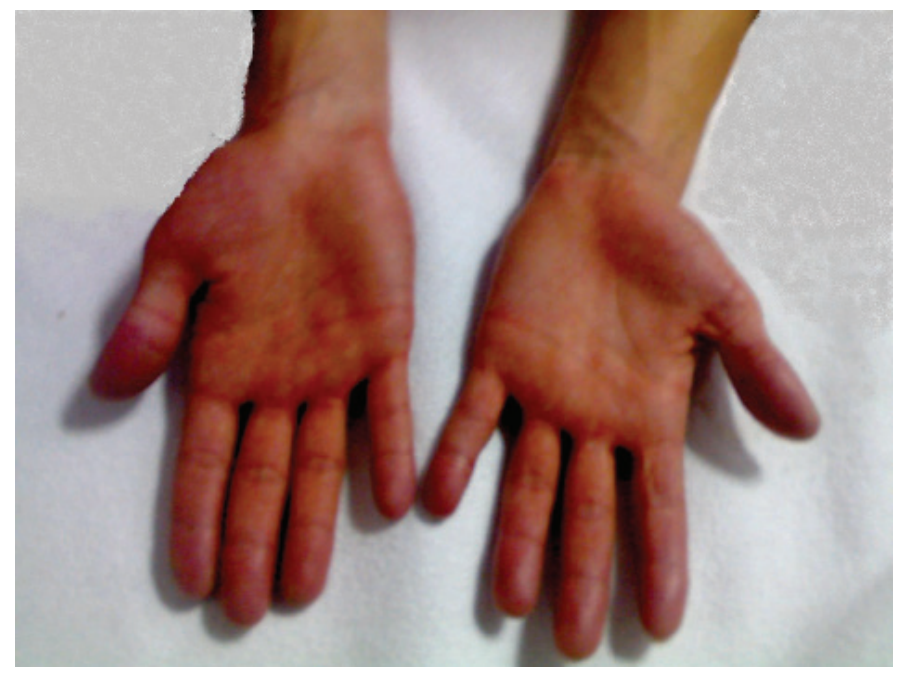

Resim 1. Hastanın el parmaklarındaki kızarıklık, soyulma ürün alerjileri kadınlarda daha sık görülmektedir. Kozmetiklere karşı mesleksel alerjik reaksiyonlar en sık kuaförlerde görülmekte ve meslekle ilişkili en sık kaynak saç ürünleridir5. İki yüz dokuz kuaför üzerinde Italya'da yapılan bir çalışmada \% 43,8'inde saç bakım serilerindeki bir veya daha fazla antijene karşı pozitif yama testi saptanmışır6. Kozmetik ürünlerle ilişkili alerjik reaksiyonlara en sık koku ve koruyucu maddeler neden olmaktadır ${ }^{7}$. Warchaw ve arkadaşlarının 5 yaptığı çalışmada kadınların \%59,4'ünde, erkeklerin \%73,5'inde gözlenen reaksiyonlardan bu maddeler sorumlu olarak bulunmuştur. Diğer sık görülen kozmetik ürünlerle ilişkili maddelerden biri de CAPB'dir. CAPB şampuan ve kozmetik ürünlerde bulunan surfaktan yapısındaki bir maddedir. Özellikle tip IV aşırı duyarlılık reaksiyonlarına yol açmaktadır. Kadın ve erkeklerde kozmetiklerle ilişkili en sık 10 allerjen arasında yer almaktadır. Özellikle saç bakım ürünleri ve deri temizleyicileri ile ilgili reaksiyonlarda sık rastlanan bir allerjendir 5 . Kontakt duyarlıık geliştirme sıklığı \%3-\%7,2 arasında tahmin edilmektedir². Olguların \%59'unda yüz, saçlı deri ve boyunda dermatite yol açarken \%12,7'sinde el dermatitine yol açar. El dermatiti genellikle kuaförlerde görülmektedir1. De Groot ve arkadaşlarının 8 yaptığı çalışmada 20 CAPB alerjili hastanın 8'inin kuaför olduğu saptanmış ve el dermatitli kuaförlerde \%1'lik CAPB ile yama testinin rutin olarak yapılması önermişlerdir. CAPB oluşumunda ara ürünler olan dimetilaminopropilamin (DMAPA) ve kokamidopropil dimetilaminin (amidoamin veya kokamidoamin olarak da bilinen) asıl alerjiden sorumlu ajanlar olduğu ileri sürülmüştür. İspanya'da yapılan bir çalışmada DMAPA'ya karşı duyarılı̆̆ı olan 3 hastaya CAPB ile yama testlerinde duyarlılık saptanmamış. CAPB içeren şüpheli ürünlere tekrar maruz bırakıldığında ise hastaların lezyonlar tekrarlamış. Bu nedenle CAPB alerjilerinden sorumlu ajanların DMAPA ve amidoamin olduğu öne sürülmüştür9.

Foti ve ark.' larının 10 çalışmasında CAPB karşı duyarlıığı olan 10 hastaya DMAPA $(\% 1)$ ve amidoamin $(\% 0,5$ ve $\% 0,25)$ ile yama testleri uygulamışlar ve tüm hastalarda DMAPA ve amidoamine karşı pozitif yanıt elde etmişlerdir. Li11 tarafından yapılan çalışmada alerjik kontakt dermatit şüphesi ile başvuran 429 hastaya yama testleri uygulanmış. Olguların $10(\% 2,3)^{\prime}$ ünde DMAPA'ya reaksiyon saptanmış. Bu olguların

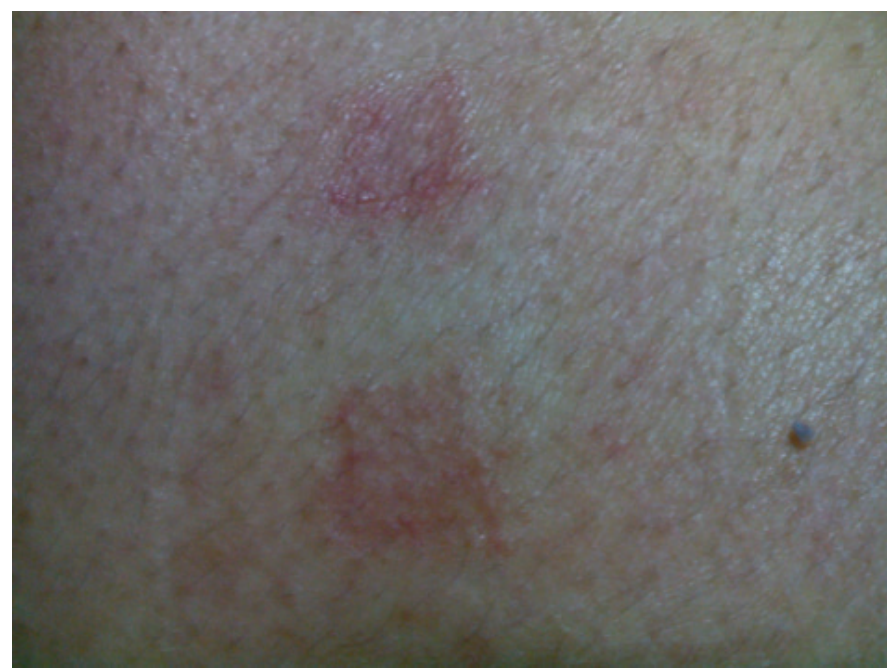

Resim 2. Hastanın deri yama testindeki pozitif reaksiyon 
6'sında ise CAPB ile reaksiyon saptanmıs. Kozmetik alerjisi şüphesi olanlarda DMAPA ve CAPB'nin her ikisi ile yama testlerinin yapılması gerektiği belirtilmiştir. Bizim olgumuz da literatüre benzer olarak kuaförlük mesleği yapmakta olan erkekte CAPB duyarlılı̆ı saptadık. DMAPA ile test materyalimiz olmadığı için olgunun DMAPA duyarılı̆̆ını değerlendiremedik.

Kokonat dietanolamid CAPB'e benzer olarak el jeli, temizleyici ve kozmetik ürünlerde bulunan surfaktan yapısında bir maddedir. Nadiren alerjiye neden olmaktadır. Kontakt duyarlıık geliştirme sıklığı \%1,8 olarak bulunmuştur. Genellikle diğer alerjenlerle birlikte reaksiyona yol açarken CAPD ile birlikte reaksiyona yol açması nadirdir ${ }^{1}$. Brey ve arkadaşlarının ${ }^{12} 49$ CAPD duyarlılığı olan kontakt dermatitli hastalarda yaptıkları çalışmada sadece 2 hastada CDEA ile reaksiyon saptamışlardır. Warchaw ve ark.'nın5 yaptığı çalışmada deri temizleyicileri ile oluşan kontakt dermatitli olgularda en sık etiyolojik ajan olarak CDEA bulunmuştur. Finlandiya'da 1985-1992 yılları arasında CDEA bağlı mesleksel AKD'li 6 olgu bildirilmiş. Bunların hiçbirinde CAPB'e karşı reaksiyon gözlenmemiştir ${ }^{13}$. Olgumuzda hem CAPB hem de CDEA'ya karşı reaksiyon saptanmıştır.

Alerjik kontakt dermatitin tedavisinde temel ilke, sorumlu alerjenden kaçınılmasıdır. Topikal ve oral steroidler kısa süreli semptomatik tedavide kullanılabilir. Hastamızın duyarlı olduğu maddelerle teması kesildikten sonra AKD'i iyileşti ve 1 yıllık izlemde tekrarlamadı.

Sonuç olarak, kontakt dermatitli hastalarda ayrıntılı öykü alınması (mesleği dahil), kullanılan maddelerin öğrenilmesi ve bunlarla yama testlerinin yapılması tanıda önemlidir.

\section{Kaynaklar}

1. Reitschel RL, Fowler JF: Fisher's contact dermatitis. 6'ıncı Baskı. Hamilton (ON), BC Decker Inc, 2008;266-318.

2. Jacob SE, Amini S: Cocamidopropyl betaine. Dermatitis 2008;19:157-60.

3. Romaguera C, Camarasa JM, Alomar A, Grimalt F: Patch tests with allergens related to cosmetics. Contact Dermatitis 1983;6:167-8.

4. Adams RM, Maibach $\mathrm{HI}$ : A five-year study of cosmetic reactions. J Am Acad Dermatol 1985;13:1062-9.

5. Warshaw EM, Buchholz HJ, Belsito DV, et al: Allergic patch test reactions associated with cosmetics: retrospective analysis of cross-sectional data from the North American Contact Dermatitis Group, 2001-2004. J Am Acad Dermatol 2009:60:23-38

6. Iorizzo M, Parente G, Vincenzi C, Pazzaglia M, Tosti A: Allergic contact dermatitis in hairdressers: frequency and source of sensitisation. Eur J Dermatol 2002;12:179-82.

7. Penchalaiah K, Handa S, Lakshmi SB, Sharma VK, Kumar B: Sensitizers commonly causing allergic contact dermatitis from cosmetics. Contact Dermatitis 2000;43:311-3.

8. de Groot $A C$, van der Walle HB, Weyland JW: Contact allergy to cocamidopropyl betaine. Contact Dermatitis 1995;33:419-22.

9. Hervella $\mathrm{M}$, Yanguas $\mathrm{Jl}$, Iglesias $\mathrm{ME}$, et al: Contact allergy to 3 dimethylaminopropylamine and cocamidopropyl betaine. Actas Dermosifiliogr 2006:97:189-95.

10. FotiC, Bonamonte D, Mascolo G, etal: The role of 3-dimethylaminopropylamine and amidoamine in contact allergy to cocamidopropylbetaine. Contact Dermatitis 2003;48:194-8

11. Li LF: A study of the sensitization rate to cocamidopropyl betaine in patients patch tested in a university hospital of Beijing. Contact Dermatitis 2008:58:24-7.

12. Brey NL, Fowler JF Jr: Relevance of positive patch-test reactions to cocamidopropyl betaine and amidoamine. Dermatitis 2004;15:7-9.

13. Pinola A, Estlander T, Jolanki R, Tarvainen K, Kanerva L: Occupational allergic contact dermatitis due to coconut diethanolamide (cocamide DEA). Contact Dermatitis 1993;29:262-5. 